\title{
Redes sociales e iconografía
}

\author{
María Violeta PEREYRA
}

Los textos conservados en la tumba de Neferhotep (TT49) dan testimonio del grupo de parentesco del propietario de la tumba y de su vinculación con el templo de Karnak. La reiterada representación de algunos parientes femeninos de Neferhotep, por su parte, da indicio de su importancia en la dinámica social de la época. A partir de esa evidencia nos proponemos mostrar que en este caso al menos, la reintegración social del difunto en el período de la transición posamarniana apeló a la exaltación de la figura del padre de Neferhotep y de sus ancestros para mostrar la continuidad de la sólida relación establecida con el templo de Amón, sin interrupción a través del reinado de Ajenatón.

\section{Social networks and iconography}

Texts of Neferhotep's tomb (TT49) provide proof of the family relationship of the tomb's owner and his connection with Karnak Temple. The repeated representation of Neferhotep's female relatives shows the importance of social dynamic of those times. Based on this evidence we intend to prove, at least in this case, that social reintegration of the deceased, in post Amarna transition period, made reference to the exaltation of Neferhotep's "father figure" as well as of his ancestors, to show the continuity of the strong relationship established with Amun's temple, uninterrupted during Akhenaten's reign.

KEY wORDs: Epigraphy, kinship, Neferhotep, family relationship

$\mathrm{D}$ iversos autores han sostenido que la institución del estado egipcio y su monarquía se correspondieron con un modelo social cuyo fundamento está en la estructura familiar, de la que no es ajena inclusive la organización política ${ }^{1}$. Esto es perceptible en la iconografía funeraria, en la que el grupo de parentesco del propietario está representado de diversas formas, en variadas circunstancias y con diferentes cargas simbólicas.

En Mort et au-delà dans l'Égypte ancienne, Jan Assmann reconoce una imagen de la muerte como aislamiento del individuo y ruptura de la conectividad, a partir de las dos esferas en las que se desarrolla la vida del hombre: la física y la social. De acuerdo al mito osiriano, la restitución del difunto a su grupo de pertenencia es llevada a cabo por Horus y Thot, con posterioridad a la acción de Isis, Neftis y Anubis, quienes operan sobre la esfera física. Así, sostiene el autor, el principio de conectividad es el que vivifica al difunto y lo reintegra a la comunidad de los hombres por su re-socialización en el Más Allá2. Para Assmann, la frontera de la muerte se supera, pues, a partir de una relación de sentido horizontal (entre los pares que conforman la pareja Osiris-Isis) y otra intergeneracional (Osiris-Horus) de sentido vertical.

1. Cruz-Uribe, 1994: 49-53; Moreno García, 2006: 121-146.

2. Assmann, 2003: 73-77.

Fecha de recepción: 29 de enero de 2007

Fecha de aceptación: 25 de junio de 2007 
En los monumentos funerarios privados de la dinastía XVIII la presencia de miembros de la familia del propietario de cada tumba es consistente. El caso que nos ocupa es el de Neferhotep, hijo de Neby, quien fue funcionario del templo de Karnak después del episodio de el-Amarna. Su tumba de el-Khokha (TT49) constituye una de las fuentes de información para reconstruir la vida social de la elite de esa época y la conservación que en la actualidad se lleva a cabo en el monumento contribuye a un mejor reconocimiento de su registro epigráfico, en el que se encuentran varios miembros de su grupo de parentesco. La interpretación de esos materiales -escritos y figurativos- constituye el objeto de nuestro presente estudio, que abarca por lo menos a cuatro generaciones de servidores del templo de Amón.

Desde una perspectiva general, podemos afirmar que en torno al parentesco se articularon las redes de alianza entre grupos y facciones identificables en la información que preservan las tumbas privadas del período del imperio. Nuestra hipótesis de trabajo asume, en consecuencia, que la referencia textual y figurativa de los ancestros de Neferhotep en su tumba se justifica por la necesidad del propietario del monumento de exhibir sus vínculos de parentesco por ser expresivos de su posición social en un período de transición política y religiosa, pero también porque cargan con una fuerte connotación simbólica explícita en la epigrafía.
En la necrópolis tebana de los nobles, sólo TT271 es con certeza del mismo reinado que TT49, en tanto que son igualmente escasas las tumbas atribuibles a los de Tutanjamón y Horemheb $^{3}$. Otros monumentos funerarios privados contemporáneos de los de Neferhotep y de Nay se descubrieron en las necrópolis de Saqqara ${ }^{4}$ y de Awlad Azzaz . Dada esta circunstancia y el hecho de haber vivido el primero de ellos bajo varios soberanos, la evidencia que provee la rica epigrafía de su tumba contribuye al conocimiento de la sociedad en el período posamarniano, pero además puede ser interpretada en una perspectiva diacrónica que se remonta al reinado de Ajenatón.

En un estudio anterior ${ }^{6}$ planteamos la identificación de algunos de los personajes representados en TT49 a partir del análisis de su iconografía e inscripciones. Nos propusimos interpretar allí el sentido de las referencias a miembros de la familia de Neferhotep, pero también su registro en la estatuaria y las escenas parietales en las que fueron representados. En el presente trabajo nuestro objetivo es precisar la identificación de los personajes y de los vínculos de parentesco expresados en el monumento a través del registro epigráfico, pero reconocer además su significación histórica, teniendo en cuenta la mejor visibilidad de las figuras después de su reciente limpieza ${ }^{7}$.

[ 152 ] 3. La tumba de Huy (TT40), del reinado de Tutanjamón (Davies y Gardiner, 1926), y la de Neferhotep (TT50), del de Horemheb (Hari, 1985).

4. Las tumbas de Meryra/Meryneith (TB I/14), y de Maia (BI/20) se localizaron en el acantilado del Bubastión (Zivie, 1988); las de Horemheb y de Maya (Martin, 1989 y 1993) al norte de la pirámide de Unas; la de Amoneminet en el área de la pirámide de Teti (Ockinga, 2004).

5. La tumba de Sennedyem en la vecindad de Akhmin (Ockinga, 1997).

6. "El parentesco en la epigrafía de una tumba egipcia. Abordaje interdisciplinario para una interpretación del lenguaje gráfico". Trabajo realizado en colaboración con Friedrichs y presentado a las VIIas Jornadas del Área Artes del Centro de Investigaciones de la Facultad de Filosofía y Humanidades de la Universidad Nacional de Córdoba (6-7/11/03, Córdoba, Argentina).

7. Los resultados obtenidos en las campañas de 2005 y 2006 en TT49 proveyeron información adicional al permitir reconocer en detalle y con seguridad el tratamiento figurativo de algunos de los personajes representados. 
Nuestra inquisición se enfocó en las referencias escritas y figurativas que provee TT49, y para su interpretación se atendió en particular a la distribución topográfica de los temas iconográficos y de las escenas e inscripciones dentro del monumento. Ésta contribuye a esclarecer su significado y arroja luz sobre los personajes que intervienen en cada una de ellas, además de informar acerca de su función.

Para hacer inteligible la representación de los parientes de Neferhotep en los diversos espacios de la tumba, aparte del carácter ritual de las escenas en las que toman parte y de su localización en el monumento, se examinó el tratamiento pictórico de las figuras para su interpretación contextual. Por último, la identificación de aquellos personajes cuyos nombres no se registraron -o que en la actualidad están destruidos- se llevó a cabo a partir de los códigos de representación utilizados y de su disposición en el espacio simbólico y cultual de la tumba.

\section{LA EVIDENCIA EPIGRÁFICA}

Para interpretar las representaciones figurativas y las referencias a los miembros de la familia de Neferhotep que se conservan escritas en TT49, y establecer el sentido de su presencia en el ámbito funerario en que se encuentran, tenemos en cuenta que la tumba, como unidad significativa, apela a la utilización de un diseño arquitectónico definido ${ }^{8}$ en el que cada ambiente guarda relación con su función. Las representaciones y las inscripciones jero- glíficas que nos ocupan se dispusieron en ese marco espacial, en los sectores que permitían precisar su complejidad sintáctica y semántica como mensaje funerario (fig. 1).

Las imágenes de los ancestros de Neferhotep se distribuyeron a lo largo del monumento, desde la fachada hasta el nicho de las esculturas en el interior de la superestructura, en tanto que su filiación se registró en las jambas de acceso al primer y segundo pasaje ${ }^{9}$, en las columnas de inscripción junto a las figuras de la pareja de propietarios de la tumba a ambos lados del primer pasaje ${ }^{10}$, en la pared E (lado N) y las bandas del cielorraso del vestíbulo ${ }^{11}$, $y$ en el nicho de las estatuas ${ }^{12}$.

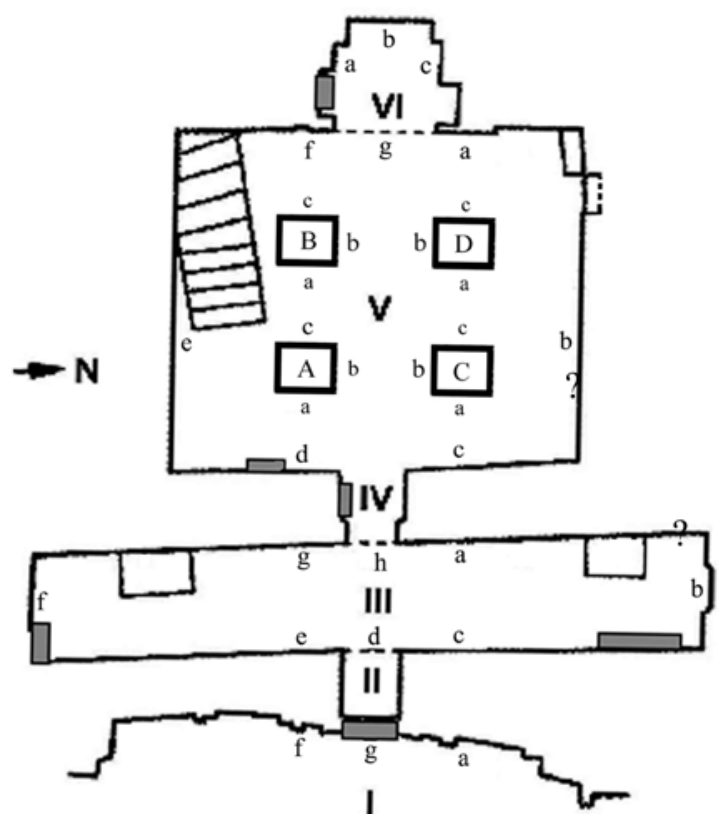

[153 ]

8. Que se corresponde al tipo VI b de la tipología de Kampp (1996: 13, fig. 1).

9. Davies, 1933: I, Pls. XXXV y XXXVIII.

10. Davies, 1933: I, Pls. XXXVI y XXXVII.

11. Davies, 1933: I, Pls. LVIII.g, LVIII.o, LIX.a, LIX.k, LIX.p y LXI.H.

12. Davies, 1933: I, Pl. LV.A

Figura 1. Localización de las representaciones de los ancestros de Neferhotep en TT49 
De los parientes del funcionario, su esposa Merytra es quien está representada con mayor frecuencia en TT49 y su presencia es consistente en todas las salas, ya sea en compañía de su esposo ${ }^{13}$ o sola ${ }^{14}$.

En cuanto a los padres de Neferhotep ${ }^{15}$, en diversas oportunidades las referencias escritas registran, sus títulos y el vínculo familiar además de sus nombres: Neby e Iwy. Su registro iconográfico, por su parte, se reitera en cinco escenas parietales de la tumba y plantea algunas cuestiones al confrontarse con las representaciones del noble que, a diferencia de aquéllas, en diversas ocasiones lo muestran anciano.

Neby e Iwy fueron retratados en pareja 1) en el dintel de acceso a la tumba, acompañando a los propietarios del monumento en la doble escena de ofrenda a Osiris y Anubis ${ }^{16} ; 2$ ) en el registro inferior del lado $\mathrm{N}$ de la pared E del vestíbulo, sentados supervisando la preparación del ajuar funerario ${ }^{17}$; en el lado $\mathrm{S}$ del segundo pasaje, recibiendo a Neferhotep en el Más Allá ${ }^{18}$, y 3) en las estatuas del nicho $\mathrm{S}^{19}$ (fig. 2).

En la capilla de culto, Iwy puede ser identificada con la dama ubicada detrás de la pareja

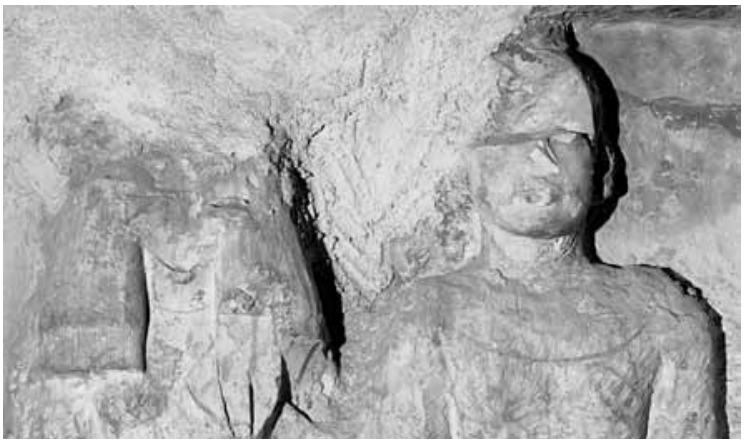

Figura 2. Estatuas de los padres (?) de Neferhotep. Detalle (Fotografia de T. Haupts, 2004)

de propietarios en la ofrenda a Ra Harajty, en el registro principal del lado $\mathrm{S}$ de la pared $\mathrm{O}^{20}$, mientras que es probable que sea Neby el sacerdote que entrega a Neferhotep el ramo de vida en el interior del templo de Amón ${ }^{21}$.

Las inscripciones que se preservaron desde el patio hasta la capilla del ka, por su parte, consignan de manera explícita esa relación de parentesco en las diversas estancias del monumento. Esto permite inferir que la filiación de Neferhotep fue considerada como un elemento destacable en el conjunto de los recursos de los que dispuso para asegurar su transfiguración y pervivencia en su morada de eternidad.

13. En la mayoría de las escenas parietales y en la gran estatua del nicho principal de TT49.

14. Son destacables la escena de su recompensa de manos de la reina, registrada en el lado $\mathrm{S}$ de la pared O del vestíbulo (Davies, 1933: II, Pl. I y I, Pls. XIV y XV) y su representación en la cara O del pilar SE de la capilla de culto (Davies, 1933: I, Pl. LII).

[ 154 ] 15. En los casos de carecer de una clara designación nominativa identificamos a los personajes representados en TT49 por su localización dentro del monumento y por su tratamiento plástico individual. Así procedimos con las estatuas y atribuimos las del nicho $\mathrm{S}$ a los padres de Neferhotep.

16. Davies, 1933: I, 50; Pereyra et al., 2006: fig. 16.

17. Podemos considerar la existencia de otra representación en la pared que enfrenta a estas figuras, perdida en la actualidad (Davies, 1933: II, Pl. II), en el registro superior de la pared y manteniendo una equilibrada correspondencia con las figuras sedentes de Neferhotep y Merytra dispuestas en el subregistro inferior (Davies, 1933: I, XXXIII).

18. Davies, 1933: I, PL. XXXIX.

19. Pereyra et al., 2006: 40.

20. Pereyra et al., 2006: fig. 25.

21. En la famosa escena del templo de Karnak representada en el registro superior de la pared N de esa sala (Davies, 1933: I, Pl. XLI y II, P1. III). 
En cuanto a los demás ancestros masculinos del funcionario que fueron registrados en TT49, la identificación de su abuelo Ptahemheb y de su bisabuelo Nebbuneb es segura, de acuerdo a la inscripción del panel $\mathrm{E}$ de la pared $\mathrm{S}$ del vestíbulo. Tal vez también se deba atribuir al primero de ellos la figura sedente ante una mesa de ofrendas ${ }^{22}$ (fig. 3).

Las representaciones de otros miembros de la familia es probable que se correspondan con las figuras de algunos de los personajes participantes en su procesión funeraria (registro superior, pared $\mathrm{E}$ del vestíbulo) ${ }^{23}$; en el banquete funerario (registro inferior, lado $\mathrm{S}$ de la pared $\mathrm{O}$ del vestíbulo) ${ }^{24}$; en las ofrendas a Ra Harajty (a ambos lados de la pared E de la capilla de culto) ${ }^{25}$ y en otras escenas rituales ${ }^{26}$. Desafortunadamente, las columnas de texto jeroglífico que podrían ayudarnos a identificarlos quedaron vacías.

Tampoco disponemos de inscripciones para atribuir con seguridad a algún pariente o allegado a Neferhotep la identidad de los personajes retratados en los grupos escultóricos de los nichos $\mathrm{N}$ y $\mathrm{S}$ de la capilla del $\mathrm{ka}^{27}$. Aunque mutiladas, el tratamiento figurativo de las estatuas del nicho $\mathrm{S}$ permite inferir que representaban a un hijo (o hija) de Neferhotep ${ }^{28}$ y a su mujer (o marido), si no a su hermano (o hermana) y su cónyuge.

También es lógico asociar las estatuas secundarias con los pozos funerarios a los

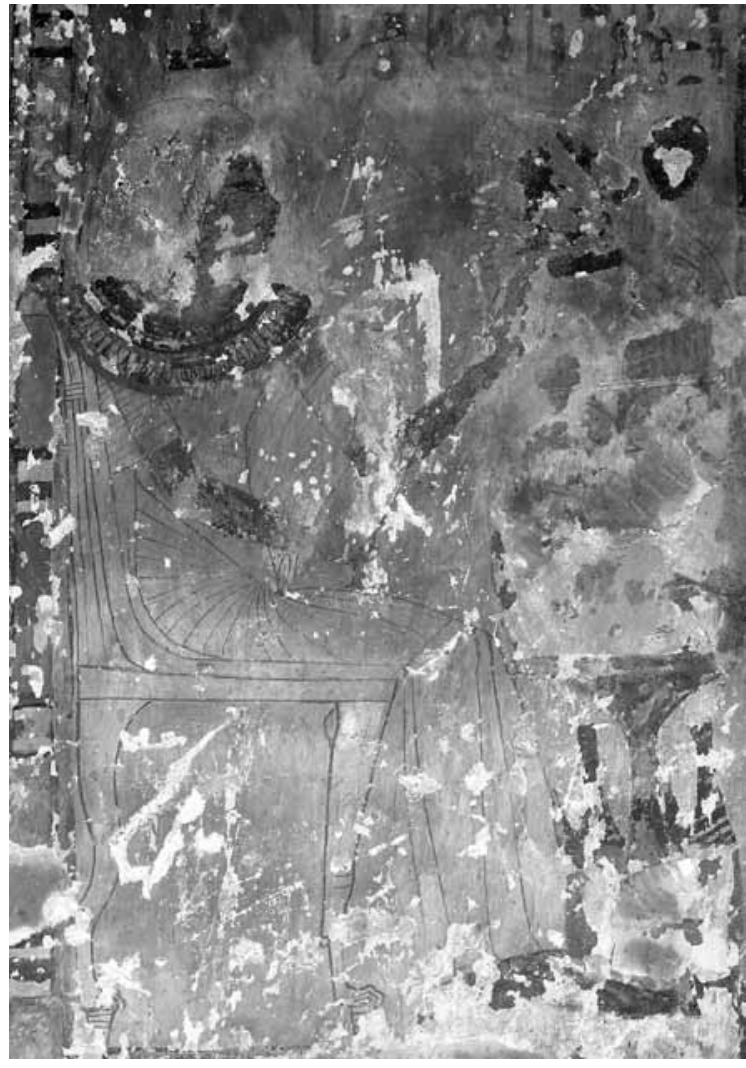

Figura 3. El abuelo de Neferhotep (Fotografía de T. Haupts, 2004)

que se accede desde el vestíbulo de TT4929. Sendos sepulcros debieron guardar estricta correspondencia topográfica con las parejas escultóricas sedentes que participan de las ofrendas en la capilla del ka y a quienes hemos reconocido en forma hipotética. Si nuestra identificación de los personajes retratados

22. Davies, 1933: I, Pl. XIX.A. Retratado con el cabello blanquecino, un rasgo del que nos ocupamos más adelante.

23. Davies, 1933: I, Pls. XX-XXIV.

24. Davies, 1933: I, Pl. XVIII.

25. Pereyra et al., 2006: figs. 24 y 25 .

26. Dispuestas en el lado N la pared O del vestíbulo (Davies, 1933: I, Pls. XXX-XXXIII) y en la cara O del pilar SO de la capilla de culto (Davies, 1933: I, Pl. LII).

27. Davies, 1933: 1, 14 .

28. Que no se mencionan en ninguna inscripción del monumento.

29. Sendos pozos funerarios fueron excavados en ambos extremos del vestíbulo de TT49 (Davies, 1933: I, 10 y Pl. VI). La entrada al sepulcro principal de TT49 se encuentra en el lado S de la capilla de culto. 
Cuadro 1

\begin{tabular}{ccc}
\multicolumn{4}{c}{ Familia de Neferhotep } \\
Nebbuneb & T & esposa ? \\
Ptahemheb & T & esposa? \\
Neby & T & Iwy \\
hermano? & $=$ & Neferhotep $T^{\top}$ Merytra \\
& & hijos ? hijas ?
\end{tabular}

en las estatuas es correcta, los padres de Neferhotep habrían sido enterrados en el sepulcro del lado $\mathrm{S}$ del vestíbulo y los de la pareja del nicho $\mathrm{N}$ en el del lado $\mathrm{N}$.

A pesar de ser una obligación -mítica y social- del hijo/heredero del difunto el cumplimiento de los rituales funerarios asociados al enterramiento y el posterior mantenimiento del culto, carecemos de pruebas para identificar a algún descendiente de Neferhotep y Merytra con el ritualista representado en la ejecución de las diversas prácticas ${ }^{30}$. No obstante, y aunque ninguna de las figuras retratadas pueda vincularse por su nombre, título o filiación con alguno de sus descendientes, podemos suponer que éstos, igual que los padres del propietario de la tumba, fueron sepultados en su monumento funerario, en las tumbas del vestíbulo.

En síntesis, la evidencia que provee la epigrafía de la tumba de Neferhotep para el lapso de cinco generaciones, aún siendo incompleta muestra que su familia estuvo constituida por lo menos por los miembros que aparecen en el cuadro 1.

\section{LA Familia de Neferhotep y SU SERVicio AL Templo de Amón}

A partir de las referencias escritas y figurativas de TT49 que hemos considerado en el apartado anterior, podemos analizar en perspectiva diacrónica las relaciones que los miembros identificados de la familia de Neferhotep mantuvieron con el estado y el templo de Karnak en particular.

Una primera observación está referida a Merytra, quien lleva los títulos usuales entre las mujeres nobles de la época: señora de la casa y cantante de Amón en el templo de Karnak. Porta además el de favorita de Hathor, señora de $\mathrm{Cu}$ sae, en su representación de la pared $\mathrm{S}$ del pasaje de entrada y en la cara $\mathrm{O}$ del pilar $\mathrm{SE}^{31}$, en tanto que el de favorita de Mut está registrado en la inscripción que la identifica en la cara $\mathrm{E}$ del pilar $\mathrm{NO}^{32}$.

Neferhotep lleva los títulos de escriba, grande de Amón, supervisor de los toros de Amón y supervisor de las neferut de Amón en el Alto y el Bajo Egipto ${ }^{33}$, lo que revela la naturaleza secular de las funciones administrativas que tuvo a cargo en su servicio al templo de Karnak.

30. Davies, 1933: I, Pls. XXIV, XXXII-XXXIII.

31. En el que está representada sola y en talla jerárquica, seguida por seis personajes secundarios dispuestos sobre tres líneas de base.

32. Davies, 1933: I, Pl. L.

33. Estos títulos se reiteran en las inscripciones a lo largo de toda la tumba. No obstante, su formulación más completa corresponde a las inscripciones del cielorraso del vestíbulo, donde también se consignaron los títulos de su padre (Davies, 1933: I, Pls. LVIII y LIX). 


\section{Cuadro 2}

\begin{tabular}{l|l|l} 
Vínculo & Nombre & Títulos \\
\hline Bisabuelo & Nebbuneb & escriba de las neferut del templo de Amón \\
\hline Abuelo & Ptahemheb & escriba de las neferut \\
\hline Padre & Neby & servidor de Amón y dignatario de Amón; escriba (?) \\
\hline hijo (?) o hermano (?) & $(?)$ & $(?)$
\end{tabular}

Los títulos de sus ancestros mayores se registraron en el panel dispuesto al E de la estela de la pared $\mathrm{S}$ del vestíbulo. Su abuelo Nebbuneb era escriba de las neferut del templo de Amón y su bisabuelo Ptahemheb escriba de las neferut. Ambos son legibles hasta el presente y muestran que habrían servido al templo de Karnak antes del período de el-Amarna.

Otro pariente masculino de Neferhotep cuya identidad y títulos no se conservaron fue representado en la estatua del nicho $\mathrm{N}$ de la capilla de culto del ka, a la que ya nos referimos en el apartado anterior.

Los parientes masculinos de Neferhotep y sus títulos se reseñan en el cuadro 2.

En cuanto a los miembros femeninos de la familia de Neferhotep documentados en su tumba, además de su mujer Merytra su madre Iwy fue retratada en el relieve del dintel de la entrada a TT49 y en la escena pintada en el segundo pasaje, como así también en el grupo escultórico del nicho $\mathrm{S}$ de la capilla del ka. En estos casos las inscripciones dan certeza de su identificación, que también puede sugerirse en otro, de acuerdo al tratamiento figurativo de una de las mujeres que componen la escena de ofrenda a Ra Harajty (lado S de la pared E de

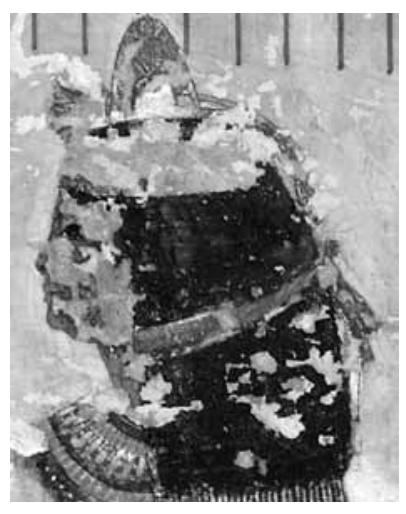

Figura 4. La madre (?) de Neferhotep. Detalle de la ofrenda a Ra Harajty (Fotografia de S. Yomaha, 2006)

la capilla de culto). Las tres figuras femeninas fueron caracterizadas por medio de elementos expresivos de su identidad. A partir de la reciente limpieza realizada en la tumba es clara la visualización de un collar shebyu $u^{34}$ en el cuello de la primera, Merytra, de una barbilla flácida en la segunda ${ }^{35}$, Iwy, y de la apariencia juvenil de la tercera (fig. 4).

El nombre de Iwy acompaña su representación del patio y se repite con sus títulos en las jambas que enmarcan la entrada a la tumba y en los relieves del primer pasaje, entre otros sectores del monumento; pero está ausente en la estatuaria y la escena de la capilla de culto. En cuanto a sus títulos, sólo lleva el

34. Un icono de la recompensa real recibida por Merytra de acuerdo a la escena del vestíbulo a la que ya hicimos referencia.

35. La representación de la vejez femenina es inusual en el antiguo Egipto (Janssen y Janssen 1996: 14), no obstante lo cual pueden mencionarse las figuras de la mujer de Irinefer (TT290) y de cuatro mujeres retratadas en TT40 (Janssen y Janssen, 1996: 25 y fig. 29). 
Cuadro 3

\begin{tabular}{l|l|l} 
Vínculo & Nombre & Títulos \\
\hline Madre & Iwy & señora de la casa; cantante de Amón \\
\hline Esposa & Merytra & señora de la casa; cantante de Amón; favorita de Mut \\
\hline hija (?) o hermana (?) & $(?)$ & $(?)$
\end{tabular}

que es habitual entre las damas de la elite imperial: señora de la casa.

No es posible identificar al tercer personaje femenino, por cuyo aspecto podría ser una hija (mejor que una hermana) de Neferhotep. Esta sugerencia tiene correlato lógico con la presentación de tres generaciones partícipes en el ritual de la ofrenda solar.

Los parientes femeninos de Neferhotep y sus títulos se recogen en el cuadro 3 .

Es seguro que Neferhotep fue funcionario del templo de Amón bajo el reinado de Ay, dado que su cartela se conserva en el vestíbulo de TT49. Pero sus representaciones indican que, lo mismo que su rey, ya era un anciano en el momento en que su tumba fue decorada.

El retrato figurativo de la vejez no es común en el arte funerario egipcio. Sin embargo, su frecuencia se hace mayor en época ramésida y las figuras de TT49 constituyen su antecedente directo ${ }^{36}$. En el monumento de Neferhotep no dudamos en considerar que de manera intencional su cabeza fue representada con la [158 ] blancura de las canas que daban cuenta de su edad y de su condición de par coetáneo de su

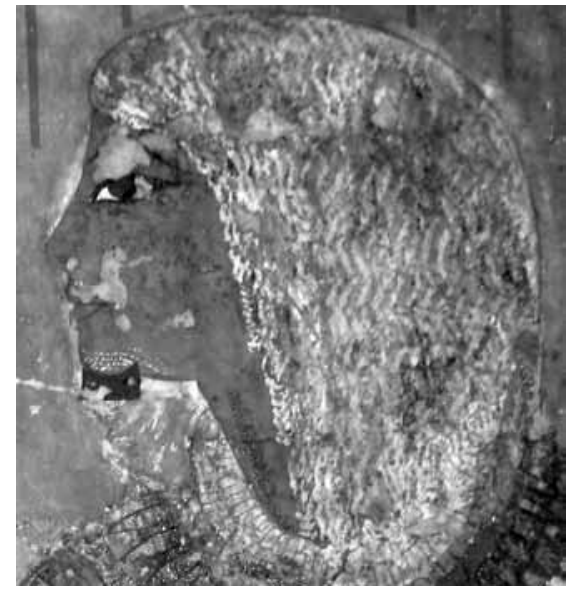

Figura 5. Neferhotep. Detalle de la escena de ofrenda a Ra Harajty (Fotografía de S. Yomaha, 2006)

rey $^{37}$, dado que el color blanco de su cabellera es perceptible en las diversas escenas de la capilla de culto ${ }^{38}$. También la flacidez corporal está indicada en los pliegues de su abultado abdomen, como otro rasgo figurativo expresivo de su vejez. La edad, está así presente en todas las ocasiones en las que fue retratado y en las que se preservó el color en la decoración parietal (fig. 5).

Los mismos recursos plásticos fueron empleados en su estatua, en la que Neferhotep fue retra-

36. Un caso destacable es el de la tumba de Pashedu (TT3), en la que la cabellera de su padre es blanca y la de su madre entrecana, igual que la de su suegra. El mismo recurso de indicación de edad fue utilizado en las tumbas de Ipuy (TT217) y de Irinefer (TT290).

37. Es probable que también el futuro Ramsés I haya sido representado como anciano en una escena de la tumba menfita de Horemheb en la que se retrató a un funcionario recompensado por el rey (tal vez Ay, si no Tutanjamón). Otro ejemplo proveniente de Saqqara se conserva en un relieve del Museo de Brooklyn ( ${ }^{\circ}$ 47.120.1. Cody, 1999: 107 y $n^{\circ} 59$ ) y por su realismo fue datado en el período inmediato posterior a el-Amarna (Fazzini, 1975: 86).

38. La iluminación dorada de su peluca, perceptible en su retrato pintado es similar al tratamiento observable en la mayoría de sus representaciones. 


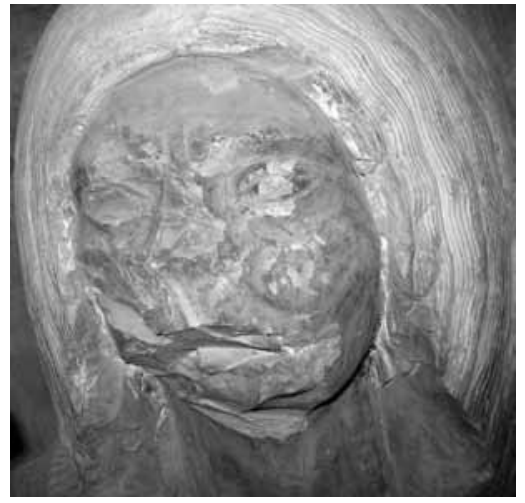

Figura 6. Detalle de la estatua de Neferhotep (Fotografía de S. Yomaha, 2006)

tado como un anciano, con la cabellera blanca, arrugas en el rostro y un vientre prominente $\mathrm{y}$ con pliegues (fig. 6).

En consecuencia, la iconografía de TT49 permite inferir que Neferhotep debía de ser ya un hombre maduro durante el reinado Ajenatón y conjeturar que la carrera de su padre Neby como funcionario fue, por lo menos en parte, contemporánea del rey hereje y del traslado de la corte a Ajetatón. Esto parece corroborarse con sus títulos, que son los más inespecíficos de todos los registrados en TT49 para los parientes de Neferhotep.

La conformación de una nueva aristocracia de hombres adeptos a Ajenatón y a su enseñanza es bien conocida y nada indica que Neferhotep o Neby formaran parte de los 'hombres nuevos' de la corte amarniana. Por el contrario, los títulos de todos los parientes que fueron registrados en TT49 sugieren que se mantuvieron leales al dios de Tebas, al que los miembros de la familia habrían servido por lo menos desde hacía tres generaciones.

Si bien el registro de la filiación en una tumba privada se explica por la necesidad del pro- pietario del monumento de mostrar su posición social, las referencias textuales y la figuración de los ancestros de Neferhotep identificados en TT49 deben interpretarse como una forma de exhibir sus vínculos de parentesco, a fin de probar su participación en el sostén de los antiguos cultos de Tebas y en particular su relación con el principal templo del dios Amón, ininterrumpida a través de cuatro generaciones.

El carácter de las referencias pudo haberse propuesto mostrar el sólido lazo existente entre los miembros de su familia y el templo de Karnak, pero lo hizo subordinado a la significación primaria del monumento: la preservación de sus moradores por la eternidad y por eso presentó a sus ancestros como partícipes de las ofrendas funerarias.

Neferhotep prestó sus servicios a Amón durante el reinado de Ay y es probable que también lo hiciera bajo Tutanjamón, su predecesor inmediato. En este caso, las dimensiones y la calidad plástica de su tumba indican que pudo ser uno de los gestores del restablecimiento del sistema de administración de los dominios de Amón y de la reasunción de la primacía de su templo, puesto que sus servicios como funcionario ameritaron que fuera distinguido por el soberano con el oro de la recompensa ${ }^{39}$.

El paralelo que podemos establecer entre el dinámico proceso histórico que caracterizó a la segunda mitad de la dinastía XVIII y los distintos miembros de la familia de Neferhotep es el que se presenta en el cuadro 4.

La próspera sociedad del Egipto imperial de mediados de la dinastía XVIII debe de haber sido el escenario del desempeño de los ancestros más lejanos de Neferhotep que conocemos: su abuelo y su bisabuelo. Sacudida por 
Cuadro 4

\begin{tabular}{l|l|l} 
Personaje & Soberano contemporáneo & Culto hegemónico \\
\hline Neferhotep & Tutanjamón y Ay Ajenatón & $\begin{array}{l}\text { Amón } \rightarrow \text { Tebas } \\
\text { Atón } \rightarrow \text { Ajetatón }\end{array}$ \\
\hline Neby & Ajetatón & Atón $\rightarrow$ Ajenatón \\
\hline Ptahemheb & Amenhotep III $?$ & Amón $\rightarrow$ Tebas \\
\hline Nebbuneb & Amenhotep III & Amón $\rightarrow$ Tebas
\end{tabular}

la reforma religiosa, la compleja vida política debió de afectar a la familia, asociada al hegemónico culto tebano de Amón. Con su persecución, la suerte del grupo perdió el favor real, que recién pudo ser restablecido en el período en que Neferhotep ya era uno de sus miembros más prominentes, si no el más exaltado. En consecuencia, como cabeza de una familia que nuevamente gozaba del privilegio y los favores del soberano y su dios, Neferhotep se presentó en TT49 como el hijo que re-socializa al padre, lo que en términos míticos actualiza la dinámica renovación del ciclo Osiris-Horus. Pero en TT49 también otros de sus parientes son partícipes de los beneficios recibidos por Neferhotep como la ofrenda que el rey da a sus servidores.

\section{Conclusiones}

Dado que la narrativa que preservan los monumentos funerarios egipcios del período imperial constituye un registro para la memoria cuya finalidad es la de fijar hechos, circunstan[ 160 ] cias y relaciones -sean éstas de carácter funerario, social, o mítico-, las inscripciones y representaciones iconográficas se constituyen en una forma de presentar el medio social de pertenencia a modo de 'pasado' que legitima los privilegios póstumos obtenidos por un funcionario. Por este motivo, los beneficios que Neferhotep disfrutó en su vida social y que se proyectaron en su destino funerario estarían justificados por su pertenencia a un linaje vinculado al servicio del templo de Amón. Tales privilegios fueron retribuidos por Neferhotep a sus antepasados a través del mantenimiento de los cultos ancestrales y haciendo partícipes a sus predecesores de las ofrendas funerarias y del banquete, mágicamente reiterados en la tumba a través de las inscripciones, de las representaciones y de los rituales de ofrenda realizados en ella.

La epigrafía de TT49 confirma el sentido de la decoración de la tumba como instrumento para la reintegración social del difunto en el período de la transición posamarniana y exalta la figura del padre de Neferhotep y de sus ancestros para mostrar la continuidad de la sólida relación establecida con el templo de Amón, ininterrumpida inclusive durante la época de la reforma de Ajenatón.

Por último, la constitución de un estado sustentado en grupos articulados sobre el parentesco permite inferir la existencia de redes interfamiliares evocadas en la epigrafía funeraria a través de los cónyuges representados.

La verificación de esta concepción de la sociedad puede hacerse al menos en forma parcial a partir de los materiales epigráficos que provee TT49. La historia de la familia de Neferhotep que hemos podido reconstruir parece haber estado asociada a los avatares sufridos por el templo de Karnak, institución que dominó la historia política, social y económica del Egipto imperial a partir de la hegemonía de su dios. 


\section{Bibliografía}

Assmann, J.

2003 Mort et au-delà dans l'Égypte ancienne. Monaco. [ed. or.: Tod uns Jenseits im alten Ägypten. München, 2001].

Cody, M.

1999100 Masterworks, en Fazzini, R.A.; Romano J.F. y Cody, M. (eds.): Art for Eternity. Masterworks from Ancient Egypt, London: 35-156.

Cruz-Uribe, E.

1994 A Model for the Political Structure of Ancient Egypt, en Silverman, D.P. (ed.): For his Ka. Essays Offered in Memory of Klaus Baer, (SAOC 55), Chicago: 4953.

Davies, N. DE G.

1933 The Tomb of Nefer-hotep at Thebes. New York, 2 vols.

Davies, N. de G.; Gardiner, A.

1926 The Tomb of Huy, Viceroy of Nubia in the Reign of Tutankhamûn ( $\left.n^{\circ} 40\right)$. (Theban Tomb Series 4). London.

FAZZINI, R.

1975 Images for Eternity. Egyptian Art from Berkeley and Brooklyn. Berkeley.

KAMPP F.

1996 Die Thebanische Nekropole zum Wandel des Grabgedankens von der XVIII. bis zur XX. Dynastie. (Theben 13). Mainz am Rhein, 2 vols.

HARI, R.

1985 La tombe du père divin Neferhotep (TT50). Genève.
JANSSEN, R.; JANSSEN J.J.

1996 Getting Old in Ancient Egypt. London.

Martin, G.T.

1989 The Memphite Tomb of Horemheb, Commander-in-chief of Tut'ankhamun. I. The Reliefs, Inscriptions and Commentary. (Excavation Memoirs Series 55). London.

1993 The Hidden Tombs of Memphis. New discoveries from the Time of Tutankhamon and Ramesses the Great. London.

Moreno García, J.C.

2006 Consideraciones sobre el papel y la importancia de la familia extensa en la organización social de Egipto en el III milenio antes de Cristo, en Campagno, M. (comp.): Estudios de parentesco y estado en el Antiguo Egipto, Buenos Aires: 121-146.

OCKINGA, B.G.

1997 A Tomb from the Reign of Tutankhamun at Akhmin. Warminster.

2004 Amenemone. The Chief Goldsmith. A New Kingdom Tomb in the Teti Cemetery at Saqqara. Oxford.

Pereyra, M.V.; Alzogaray, A.; Zingarelli, A.;

Fantechi, S.; Vera, S.; Verbeek, Ch.; Brink-

mann, S.; Graue, B.

2006 Imágenes a preservar en la tumba de $\mathrm{Ne}$ ferhotep (TT49). Tucumán.

ZIVIE, A.P.

1988 'Aper-el et ses voisins: considérations sur les tombes rupestres de la XVIIIe dynastie à Saqqarah, en Zivie, A.P. (ed.): Memphis et ses nécropoles au Nouvel Empire. Actes du Colloque International CNRS Paris, 9 au 11 octobre 1986, Paris: 103-112. 


\section{Trabajos de Egiptología Papers on Ancient Egypt}

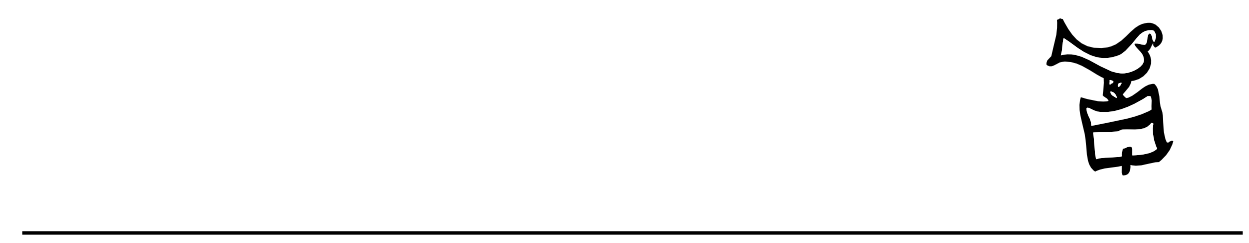

Número 5/2 2009 


\section{Actas \\ III Congreso Ibérico de Egiptología III Congresso Ibérico de Egiptologia}

Editores

Miguel Ángel Molinero Polo Covadonga Sevilla Cueva 


\title{
Editor
}

Miguel Ángel Molinero Polo

Universidad de La Laguna

\section{Consejo Editorial}

\author{
Antonio Pérez Largacha \\ Universidad de Castilla-La Mancha \\ José-R. Pérez-Accino \\ Birkbeck, Universidad de Londres \\ Covadonga Sevilla Cueva \\ Universidad Autónoma de Madrid
}

\section{Comité Científico}

Josep Cervelló i Autuori

Universitat Autònoma de Barcelona

$\mathrm{M}^{\mathrm{a}}$ José lópez Grande

Universidad Autónoma de Madrid

Josep Padró i Parcerisa

Universitat de Barcelona

$\mathrm{M}^{\mathrm{a}}$ Carmen Pérez Die

Museo Arqueológico Nacional, Madrid

Ester Pons Mellado

Museo Arqueológico Nacional, Madrid

José M. Serrano Delgado

Universidad de Sevilla

\section{Colaboradores Editoriales}

Linda Steynor

English editorial assistant

Hervé Mouriacoux

Assistant éditorial pour la langue française 
Trabajos de Egiptología está producida por Isfet. Egiptología e Historia c/ Blanco $1,2^{\circ}$

38400 Puerto de la Cruz

Tenerife-Islas Canarias

España

Maquetación: Proyecto Limón

(C) Autores de los artículos aparecidos

y Consejo Editorial de Trabajos de Egiptología - Papers on ancient Egypt

Depósito Legal: TF-2303-2009

ISSN: $1695-4750$

Imprime: Gráfica Los Majuelos, S.L.L.

imprenta@graficaslosmajuelos.com

Tfno.: 922311455 


\section{Comité Científico \\ III Congreso Ibérico de Egiptología III Congresso Ibérico de Egiptologia}

Miguel Á. Molinero Polo

Universidad de La Laguna

Presidente del Comité Organizador del III Congreso Ibérico de Egiptología

Miembro del Comité Organizador del I Encuentro de Egiptología

Josep Cervelló Autuori

Universitat Autònoma de Barcelona

Presidente del Comité Organizador del II Congreso Ibérico de Egiptologia

José Manuel Galán Allué

Consejo Superior de Investigaciones Cientificas

Director del Proyecto Djehuty, Luxor, Egipto

$\mathrm{M}^{\mathrm{a}}$ Helena Trindade Lopes

Universidad de Lisboa

Directora de la Misión Arqueológica Portuguesa en Menfis

Josep Padró i Parcerisa

Universitat de Barcelona

Director de la Misión Arqueológica de Oxirrinco

Antonio Pérez Largacha

Universidad de Castilla - La Mancha

Miembro del Comité Organizador del I Encuentro de Egiptología

José Ramón Pérez-Accino

Birkbeck College, University of London

Miembro del Comité Organizador del I Encuentro de Egiptología

$\mathrm{M}^{\mathrm{a}}$. Carmen Pérez Díe

Museo Arqueológico Nacional

Directora de la Misión Arqueológica Española en Heracleópolis Magna, Egipto

Covadonga Sevilla Cueva

Universidad Autónoma de Madrid

Miembro del Comité Organizador del I Encuentro de Egiptología 


\section{Jaramago Canora, Miguel}

La estela del rey Seankhiptah. Recientes investigaciones

Jiménez Serrano, Alejandro

Nuevos grafitos descubiertos en Garb Asuán Sur

López Grande, María José, Gregorio, Elena de

Cerámicas del Reino Nuevo con decoración pintada y plástica

halladas en Dra Abu-el Naga (excavaciones del Proyecto Djehuty)

\section{Lull García, José}

Algunas cuestiones cronológicas de la whm mswt

y la Dinastía XXI. Sobre Amenhetep, Paiankh y Herihor

\section{Martín Flores, Alfonso}

La conservación del templo de Debod. Problemas y propuestas para el futuro

Mascort Roca, Maite

El Osireion de Oxirrinco (El Bahnasa, Egipto)

\section{Méndez Rodríguez, Daniel Miguel}

La imagen de Busiris y Memnón en las fuentes clásicas

Menéndez Gómez, Gemma

Trabajo epigráfico de la tumba de Hery (TT 12)

\section{Orriols i Llonch, Marc}

Léxico e iconografía erótico del antiguo Egipto: la cópula a tergo

Parra Ortiz, José Miguel

La violencia doméstica en el Egipto antiguo

Pereyra, Maria Violeta

Redes sociales e iconografía 


\section{Pérez Díe, Carmen}

El Proyecto de investigación "Heracleópolis Magna"

(Ehnasya el Medina). Trabajos 2004-2006

Pérez-Accino, José Ramón

Texto literario y territorio geográfico: Lealtad en Sinuhé

Pons Mellado, Esther

Últimos descubrimientos en la tumba saita $n^{\circ} 14$ del yacimiento

arqueológico de Oxirrinco (El-Bahnasa): la cámara funeraria $n^{\circ} 6$

\section{Ruiz Medina, Cristobal, Delgado Corona, Noemí}

La gráfica digital aplicada a la epigrafía egipcia.

Técnicas y procedimientos visuales

\section{Rull Ribó, David}

El “vuelo mágico” del Rey en los Textos de las Pirámides

Sales, José das Candeias

A noção de trasmissão hereditária do poder nas titulaturas dos Ptolomeus

\section{Sánchez, Miguel A.}

La momia de Nesiamón del Metropolitan Museum of Art de Nueva York:

¿accidente o trasplante para la eternidad?

\section{Seco Álvarez, Myriam}

Prospección arqueológica submarina

en la zona entre el Wadi Gawasis y Marsa Alam

Serrano Delgado, José Miguel

El ritual de la Apertura de la Boca en la tumba de Djehuty (TT 11)

Sevilla Cueva, Covadonga

Revisión crítica de la figura de Montuemhat

Molinero Polo, Miguel Ángel

III Congreso Ibérico de Egiptología / III Congresso Ibérico de Egiptologia 